Article

\title{
Anethole Isomerization and Dimerization Induced by Acid Sites or UV Irradiation
}

\author{
Hans T. Castro, Jairo René Martínez * and Elena Stashenko \\ Chromatography Laboratory, CIBIMOL, Research Center of Excellence CENIVAM, Building 45, \\ Universidad Industrial de Santander, Carrera 27 calle 9, Bucaramanga, Colombia \\ * Author to whom correspondence should be addressed; E-Mail: rene@ tucan.uis.edu.co; \\ Tel.: +57(7)6456737; Fax: +57(7)6358210.
}

Received: 21 May 2010; in revised form: 21 June 2010 / Accepted: 25 June 2010 /

Published: 22 July 2010

\begin{abstract}
The formation of cis-anethole and various dimers as a result of the exposure of trans-anethole to microporous solid acids (dealuminated HY zeolites), or UV-Vis irradiation was established by means of high resolution gas chromatography coupled to mass spectrometry. 3,4-bis-(4-Methoxyphenyl)-(E)-hex-2-ene was the most abundant compound among eight different methoxyphenyl-disubstituted hexenes produced by electrophilic addition and elimination reactions induced by HY zeolites. (1a,2a,3b,4b)-1,2bis(4-Methoxyphenyl)-3,4-dimethylcyclobutane was the principal component in the mixture of 5 methoxyphenyl-disubstituted cyclobutanes found, together with cis-anethole, after UV-Vis irradiation of a trans-anethole solution in toluene.
\end{abstract}

Keywords: trans-anethole; photoisomerization; HY zeolite; cis-anethole; dimerization

\section{Introduction}

trans-Anethole (1a) is one of the main constituents of anise, clove, cinnamon and thyme essential oils [1-3]. trans-Anethole-containing oils are widely used in the food and liquor industries [4], although their use has been the subject of discussion due to the formation of cis-anethole (1) when trans-anethole is exposed to UV radiation or acidic conditions. cis-Anethole is toxic, and possesses an unpleasant scent and flavor [5]. We have previously reported that isomerization of trans-anethole takes place during the catalytic transformation of anise oil over zeolite Y [6]. 
Zeolites are porous crystalline aluminosilicates formed by $\left[\mathrm{SiO}_{4}\right]^{-4}$ and $\left[\mathrm{AlO}_{4}\right]^{-5}$ tetrahedral units. The relative amounts of these two building blocks determine the negative charge of the framework. This charge is compensated by the presence of counterions such as sodium, calcium or proton. Protonic dealuminated zeolites have found important applications as petroleum cracking catalysts. They contain Brønsted-type acid sites associated to framework Al [7]. Their use as catalysts is mainly related to their high acidity [8]. In this work we present the results of GC-MS analysis of the products (which included anethole dimers) resulting from the exposure of trans-anethole to HY zeolites, at 30, 60 and $90{ }^{\circ} \mathrm{C}$. Details of the hydrogen transfer between zeolite and trans-anethole were based on GCMS analysis of the reaction products obtained when deuterated acid zeolites, HDY, were used.

trans-Anethole exposure to UV radiation and its chemical transformation have been investigated by different authors. Lewis and Kojima $[9,10]$ studied trans-anethole photoisomerization at two excitation wavelengths, $\lambda_{\text {exc }}(281$ and $313 \mathrm{~nm})$, under different reactant concentrations, and in the absence or presence of various electron acceptors. Among their results, the authors highlighted the formation of cis-anethole and five dimers, products of [2+2] cycloaddition and electron transfer. One dimer $(\mathbf{6 e}$ in our work) was reported as the only one formed from trans-anethole; whereas a different dimer ( $6 \mathbf{c}$ in our work) was formed from trans-anethole only in the presence of electronic acceptors (cyanoanthracene, CA, 9,10-dicyanoanthracene, DCA, and 1,4-dicyanobenzene, DCB). We present results on the study of UV-Vis-induced isomerization and dimerization of trans-anethole in toluene, which indicate that dimer formation could take place without the addition of electronic acceptors.

\section{Results and Discussion}

\section{1. trans-Anethole treatment with HY zeolites}

A total of nine compounds ( $>0.1 \%$ ) were tentatively identified by means of GC-MS of the mixture obtained after exposure of trans-anethole to $\mathrm{HY}$ zeolites at 30,60 and $90{ }^{\circ} \mathrm{C}$, for $5 \mathrm{~h}$. The distinction between geometrical isomers was based on the comparison of their molecular ion abundances in their mass spectra, and some characteristic ion-fragments. $(E)$-geometry was associated with the more stable molecular ion of the two isomers. Since there were no standard substances available, dimer structure assignment relied strongly on the comparison of typical fragment losses found in their mass spectra and on the structures which appear in Scheme 1. Table 1 presents the relative amounts (\%) of transanethole and its transformation products. The structural formulae of dimers $\mathbf{2 a - 5} \mathbf{b}$ appear in Scheme 1. Dimer 5b (20-63\%) was the most abundant compound obtained under the conditions presented in Table 1. cis-Anethole (1b, 1-2\%), the dimers $\left[\mathrm{M}^{+\bullet}, \mathrm{m} / \mathrm{z} 296\right] \mathbf{2 a}(0.4-2.7 \%), \mathbf{2 b}(0.7-4 \%)$, dimers 3a and $\mathbf{3 b}(1-23 \%), \mathbf{4 a}(0.4-5 \%), \mathbf{4 b}(0.71-11 \%)$ and $\mathbf{5 a}(<0.1 \%)$ were also found as transformation products. 
Scheme 1. Proposed formation routes for dimers $\mathbf{2 a}-\mathbf{5 b}$ from trans-anethole (1a).
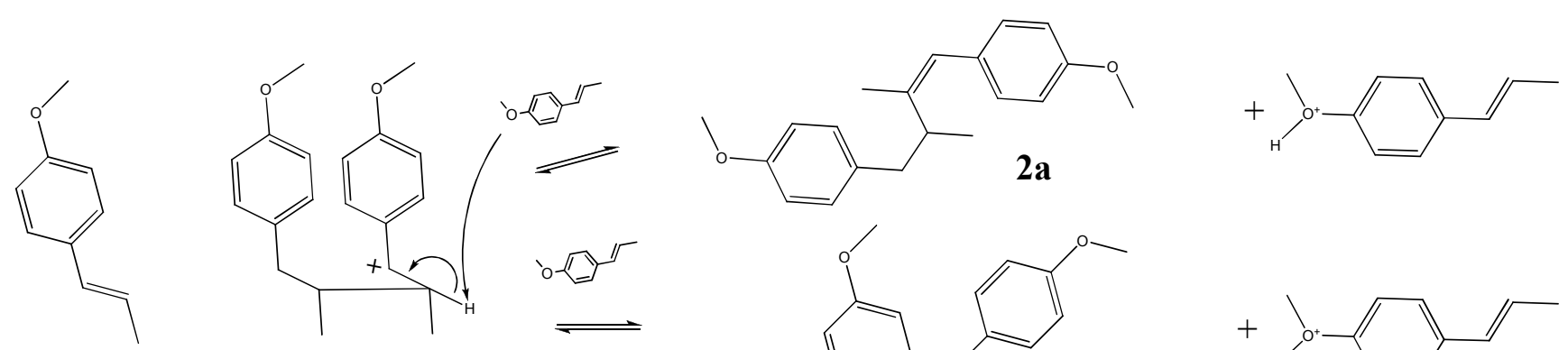

$$
\mathrm{H}^{\mathrm{H}(\mathrm{FAC})} \text { है। }
$$
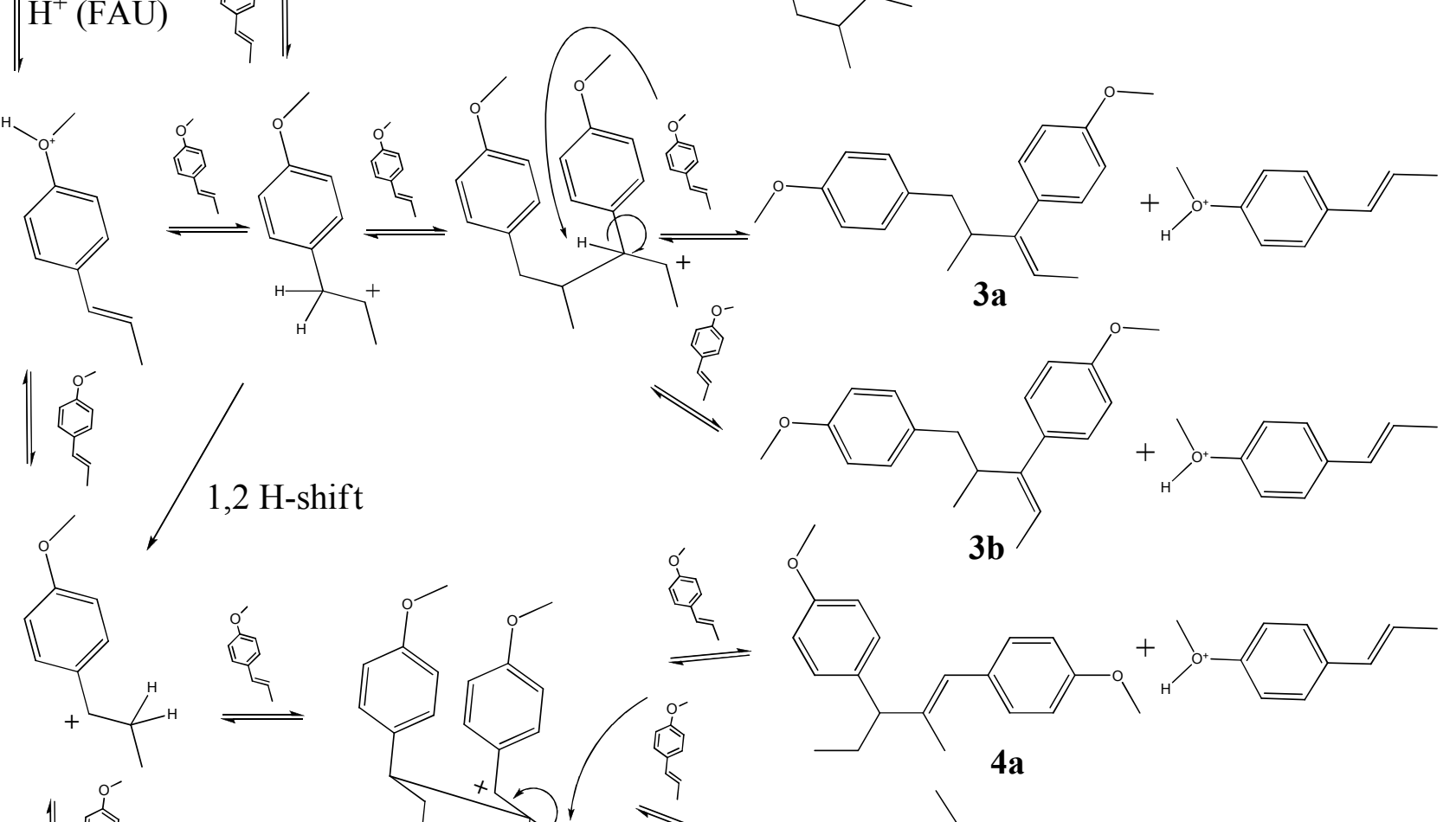<smiles>CC=Cc1ccc(OC)cc1</smiles>
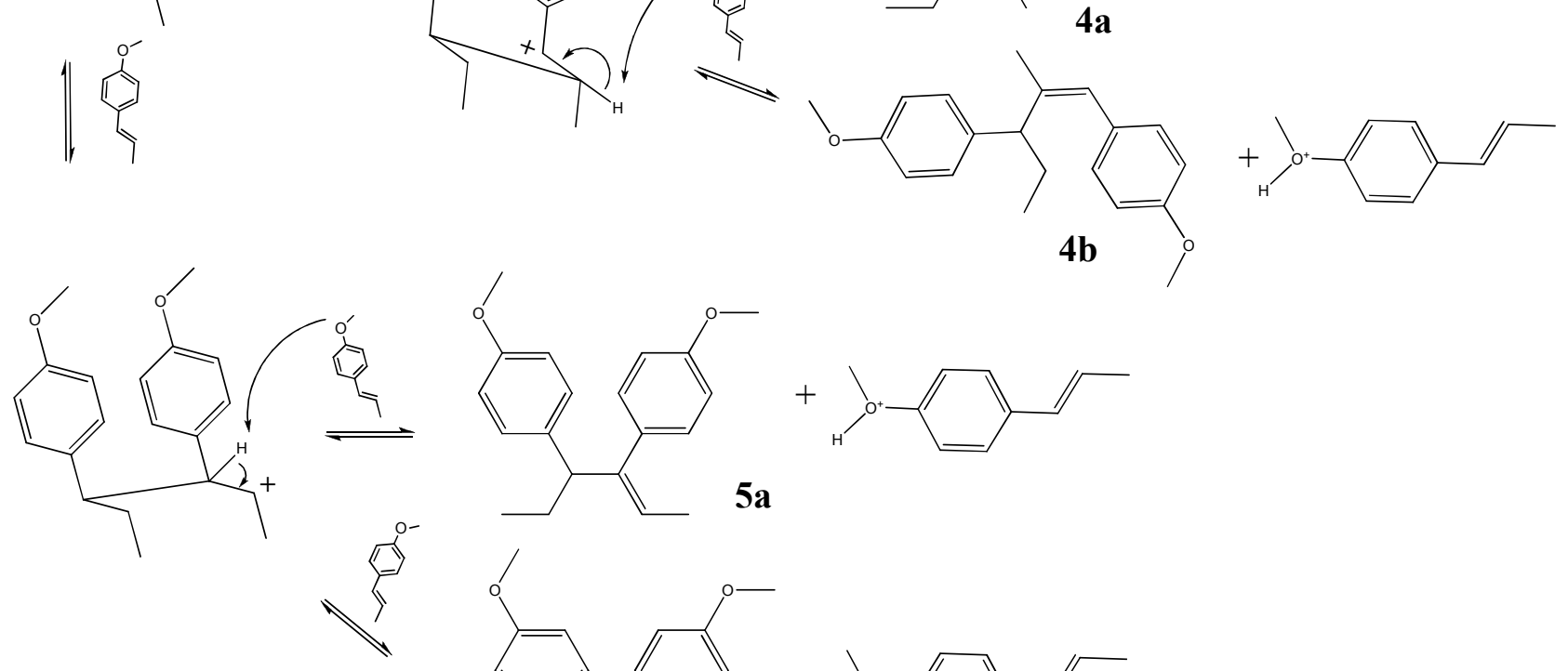

$5 \mathbf{a}$

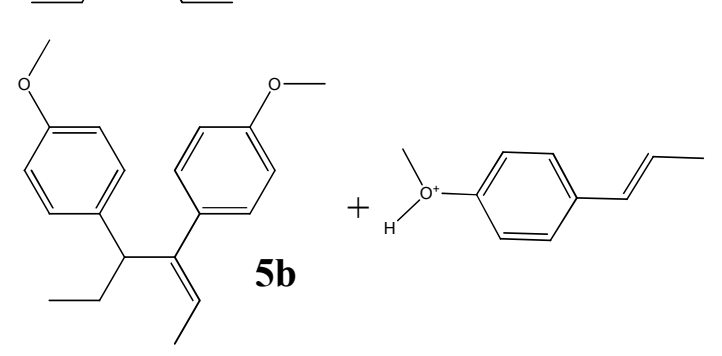


Table 1. Relative amounts of trans-anethole and its transformation products $(>0.1 \%)$, after its exposure to HY zeolites $(5 \mathrm{~h})$.

\begin{tabular}{|c|c|c|c|c|c|c|c|c|c|c|}
\hline \multirow[b]{3}{*}{ Compd. } & \multirow{3}{*}{\begin{tabular}{|l} 
Zeolite \\
T, ${ }^{\circ} \mathbf{C}$
\end{tabular}} & \multicolumn{9}{|c|}{ Relative amount, $\%^{a}$} \\
\hline & & \multicolumn{3}{|c|}{ HY1 } & \multicolumn{3}{|c|}{ HY2 } & \multicolumn{3}{|c|}{ HY3 } \\
\hline & & 30 & 60 & 90 & 30 & 60 & 90 & 30 & 60 & 90 \\
\hline \multirow{2}{*}{\multicolumn{2}{|c|}{$\begin{array}{l}\text { cis-Anethole } \\
\text { trans-Anethole }\end{array}$}} & $0.3 \pm 0.02$ & $1.9 \pm 0.24$ & $0.8 \pm 0.01$ & $0.2 \pm 0.01$ & $1.2 \pm 0.80$ & $0.9 \pm 0.11$ & $0.2 \pm 0.03$ & $1.2 \pm 0.08$ & $0.4 \pm 0.06$ \\
\hline & & $99 \pm 0.02$ & $45.0 \pm 0.80$ & $9.0 \pm 0.86$ & $99 \pm 0.01$ & $30 \pm 23$ & $12 \pm 1.1$ & $99.0 \pm 1.7$ & $76 \pm 1.4$ & $8.0 \pm 1.9$ \\
\hline \multicolumn{2}{|c|}{$\mathbf{2 a}$} & --- & $2 \pm 0.17$ & $3 \pm 0.16$ & --- & $2.7 \pm 0.92$ & $2 \pm 0.08$ & --- & $0.4 \pm 0.18$ & $1.4 \pm 0.17$ \\
\hline \multicolumn{2}{|c|}{$\mathbf{2 b}$} & --- & $1.0 \pm 0.08$ & $0.9 \pm 0.03$ & --- & $1.7 \pm 0.74$ & $4 \pm 0.24$ & --- & $0.7 \pm 0.05$ & $2.6 \pm 0.27$ \\
\hline \multicolumn{2}{|c|}{ 3a. 3b } & --- & $2.0 \pm 0.06$ & $9.0 \pm 0.03$ & --- & $5 \pm 2.02$ & $9 \pm 0.09$ & --- & $1.0 \pm 0.19$ & $23 \pm 2.2$ \\
\hline \multicolumn{2}{|c|}{$4 \mathbf{a}$} & --- & $1.0 \pm 0.08$ & $3 \pm 0.04$ & --- & $1.0 \pm 0.38$ & $5 \pm 0.06$ & --- & $0.45 \pm 0.05$ & $2.2 \pm 0.18$ \\
\hline \multicolumn{2}{|c|}{$4 b$} & --- & $2.0 \pm 0.05$ & $11 \pm 0.11$ & --- & $3.0 \pm 1.14$ & $7 \pm 1.3$ & --- & $0.71 \pm 0.06$ & $5.9 \pm 1.2$ \\
\hline \multicolumn{2}{|c|}{$5 a$} & --- & tr & tr & --- & $t r$ & $t r$ & --- & $t r$ & $t r$ \\
\hline \multicolumn{2}{|c|}{$5 b$} & --- & $45 \pm 0.30$ & $63 \pm 0.92$ & --- & $55 \pm 18$ & $60 \pm 0.4$ & --- & $20 \pm 1.2$ & $57 \pm 5.6$ \\
\hline
\end{tabular}

${ }^{\mathrm{a}}$ Mean $\pm \mathrm{s}(\mathrm{n}=3) ; \operatorname{tr}=\operatorname{trace}(<0.1 \%)$

The relative amount of dimers increased with temperature (Table 1), whereas cis-anethole was formed in higher amount at $60{ }^{\circ} \mathrm{C}$ than at either 30 or $90{ }^{\circ} \mathrm{C}$. This suggests that competition between isomerization and dimerization exists and it is consistent with the existence of a common intermediate, i.e. protonated anethole, for both processes. The increase of the dimers as the temperature was incremented could be explained by a higher reaction rate for dimerization than for isomerization.

There are very few publications in the scientific literature on the dimers presented in Table 1. Structures 3a-5b appeared in studies on biological activity and synthetic estrogens carried out in the first half of the last century [11,12]. Dimer $\mathbf{5 b}$ was mentioned by Whitmore in the context of a study on olefin polymerization with acid catalysts [13]. Scheme 1 contains the proposed formation scheme for dimers $\mathbf{2 a - 5 b}$. The two intermediary carbocations resulting from protonation of the trans-anethole double bond bind each one with a neutral molecule at two different locations. The most stable carbocation, stabilized by resonance, leads to dimers $\mathbf{4 a}-\mathbf{5 b}$. The second carbocation produces the less abundant dimers $\mathbf{2} \mathbf{a}-\mathbf{3 b}$. The orientation of the attack of the incoming trans-anethole molecule on the carbocation determines whether the $\mathbf{a}$ or $\mathbf{b}$ isomer is formed. Although only the trans-isomer was employed in the scheme proposed in Scheme 1, in principle, some of the dimers $\mathbf{2 a - 5} \mathbf{b}$ could also result from the addition of a molecule of cis-anethole to either cationic intermediary. However, the very low cis-anethole amounts make this a rare event.

\subsection{Transformation of trans-anethole exposed to deuterated zeolite, HDY}

Based on the in situ ${ }^{13} \mathrm{C}-\mathrm{NMR}$ determination of alkoxides, various studies [14-20] have proposed a carbenium-mediated mechanism for trans-anethole isomerization or oligomerization. Since both reactions take place in the same medium, it is possible that some dimers result from the reaction of a just-formed cis-anethole molecule with the cation obtained from the highly abundant trans-anethole. As evidenced in their mass spectra (Figure 1), peaks corresponding to cis- or trans-anethole 
fragmentation products which do not contain methoxy groups, incorporate deuterium. The presence of deuterium in both cis- and trans- anethole after the treatment of pure trans-anethole with deuterated faujasite supports the proposed formation scheme in which isomer interconversion occurs (Scheme 1).

Figure 1. Mass spectra (EI, 70eV) of anethole isomers and their deuterated analogs formed after the exposure of trans-anethole to deuterated acid faujasite, HDY. A. trans-Anethole and its isotopomer. B. cis-Anethole and its isotopomer.

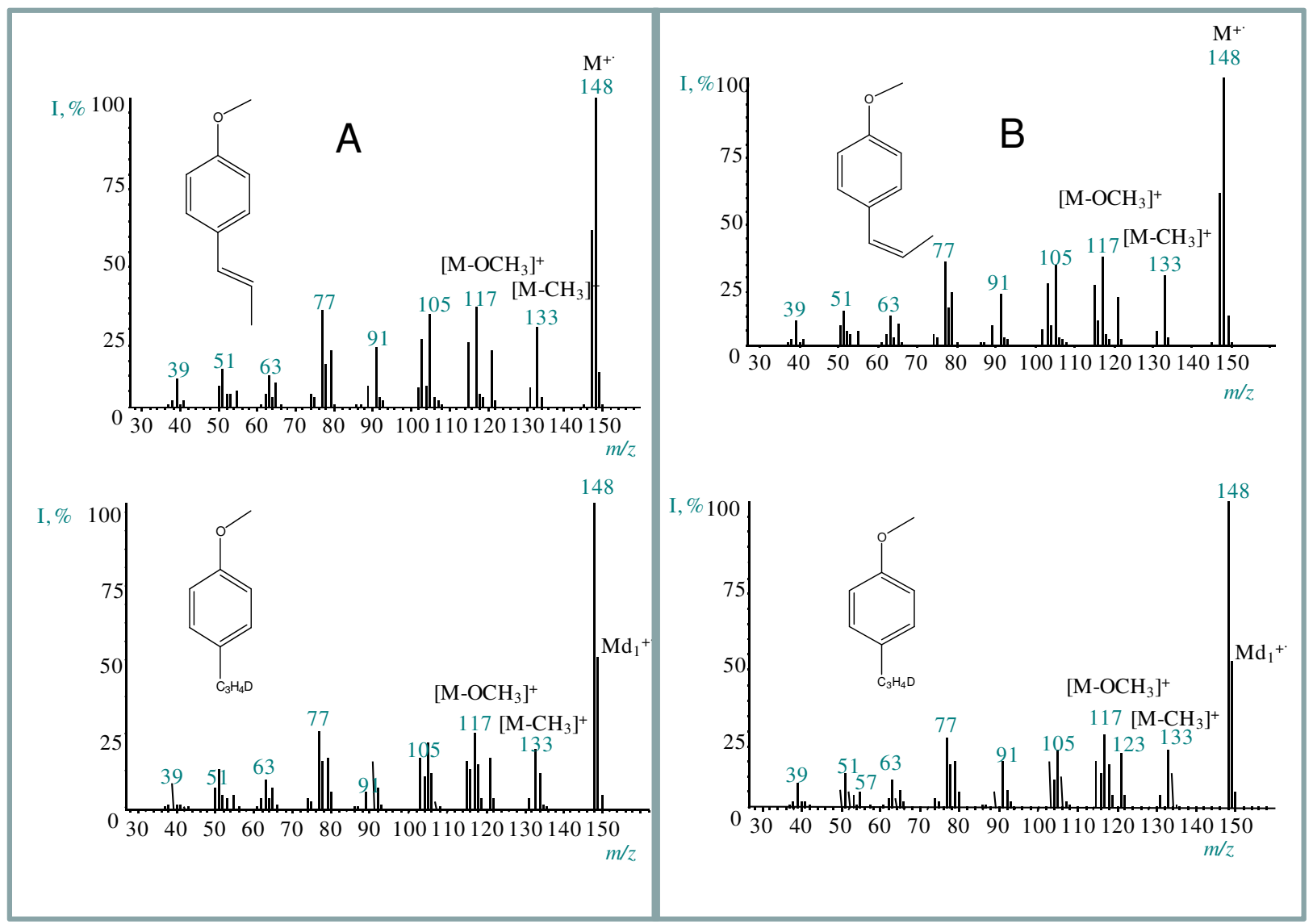

The cis-anethole mass spectra of Figure 1 were obtained from the GC-MS analysis of the products of trans-anethole exposure to either acidic faujasite, HY, or deuterated acidic faujasite, HDY, allowing us to affirm that cis-anethole formation was due to the zeolite treatment. The ratio of characteristic fragment ion abundances in the mass spectrum of deuterated $\mathrm{cis}$-anethole $(\mathrm{m} / \mathrm{z}, 117 / 118=22 / 26 ; \mathrm{m} / \mathrm{z}$ $133 / 134=19 / 18 ; \mathrm{m} / \mathrm{z} 148 / 149=100 / 77)$, compared to those of cis-anethole formed on the nondeuterated faujasite HY $(\mathrm{m} / z, 117 / 118=33 / 5 ; \mathrm{m} / \mathrm{z}, 133 / 134=25 / 4 ; \mathrm{m} / \mathrm{z} 148 / 149=100 / 14)$, showed an increased abundance of deuterated cis-anethole when HDY was used. Thus, an electrophilic deuterium addition to the $\mathrm{sp}^{2}$ carbon of the trans-anethole double bond, takes place during the isomerization or dimerization processes.

The ratios of the ion abundances at $m / z 148$ and 149 of deuterated trans-anethole are similar to those observed in the deuterated cis-anethole mass spectrum. This agrees with the existence of an intermediary carbocation that gives rise to either isomer at a similar rate. An isomerization scheme is proposed in Scheme 2. The relatively high abundance of $\mathrm{m} / \mathrm{z}, 149$ in the mass spectra of isomerization products (both cis- and trans-antehole), indicative of the presence of deuterium, suggests that the 
neutral product may be formed by the loss of a proton different from that which participated in the electrophilic addition.

Scheme 2. Proposed scheme for trans-anethole isomerization over deuterated faujasite, HDY.<smiles>[2H][O+](C)c1ccc(/C=C/C)cc1</smiles>

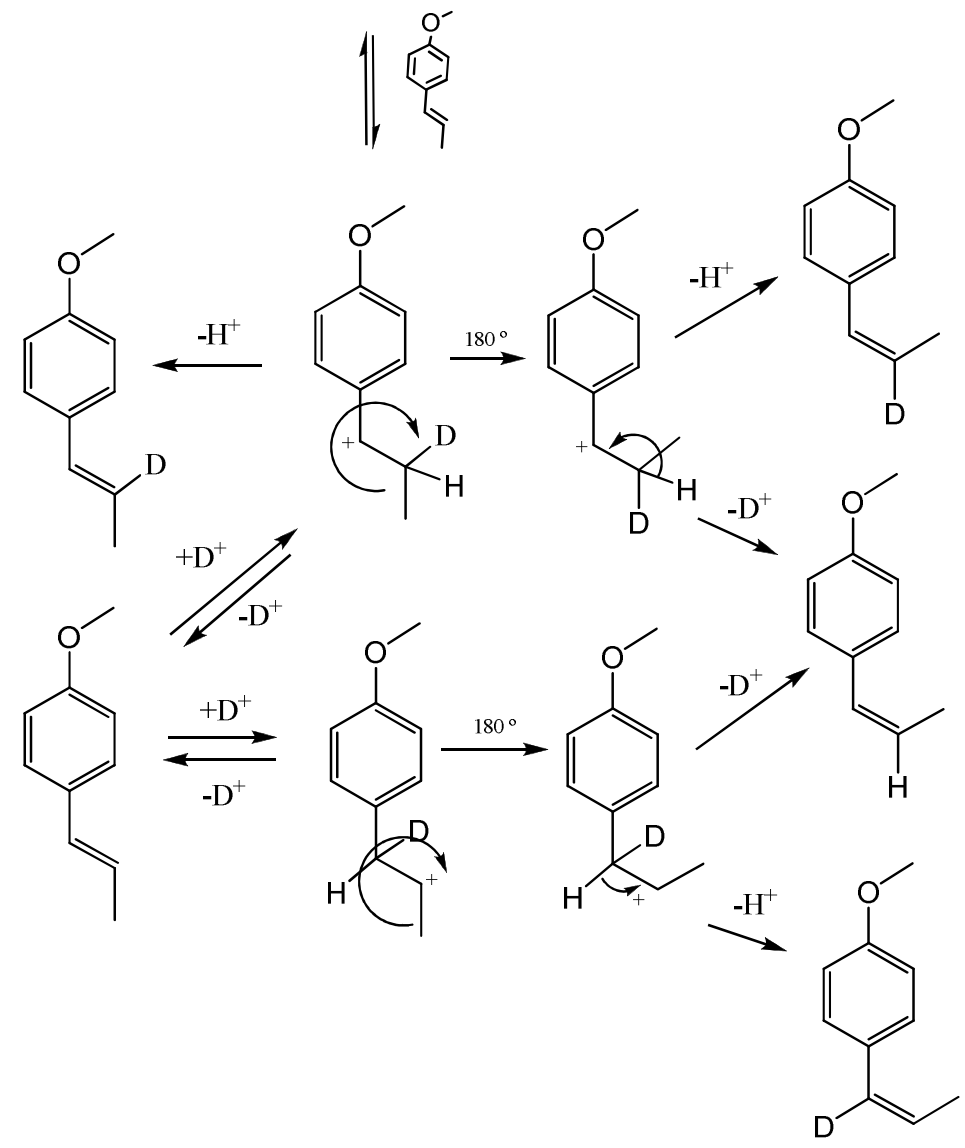

Typical mass spectra of the dimers formed after trans-anethole exposure to deuterated faujasite HDY, appear in Figure 2. Ions at $m / z 297$ and 298 in the mass spectra of all dimers indicate single and double deuteration, respectively, which results from the participation of one or two deuterated molecules of either cis- or trans-anethole. The signal of the non-deuterated molecular ions $(\mathrm{m} / \mathrm{z} 296)$ was in all cases of lower intensity than that of the monodeuterated dimers $(\mathrm{m} / z$ 297). Scheme 3 shows a mechanism proposed for the dimerization process, applied to the case of dimer $\mathbf{5} \mathbf{b}$, which was the most abundant product. In the observed mass spectra (electron impact ionization, $70 \mathrm{eV}$ ), peaks of the various deuterated ions derived from these structures were of high intensities (Figure 2). 
Figure 2. Mass spectra (EI, $70 \mathrm{eV}$ ) of anethole dimers formed as a result of trans-anethole exposure to deuterated faujasite HDY.
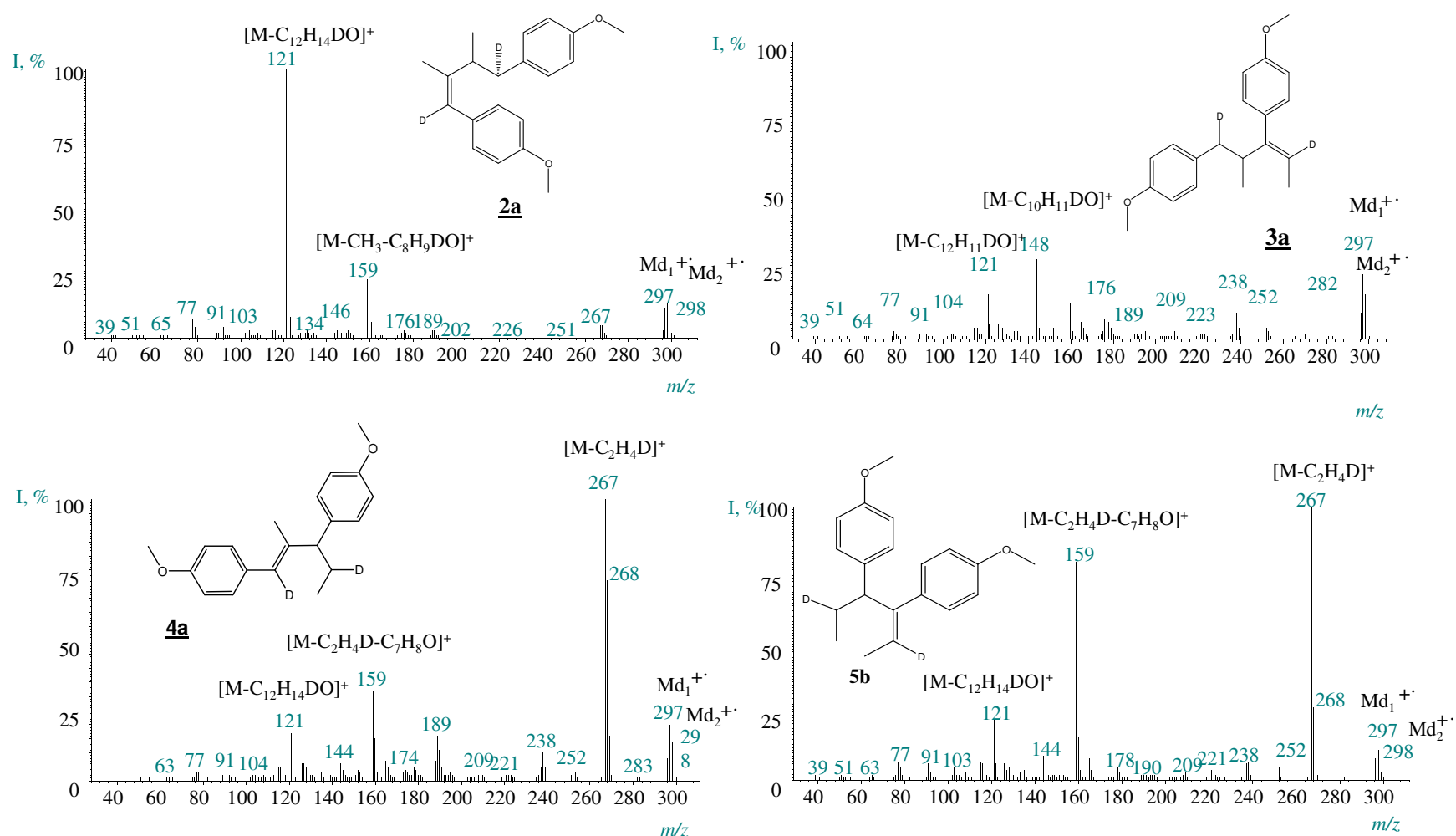

\section{3. trans-Anethole phototransformation}

Figure 3 shows the chromatographic profiles of the mixtures that resulted from the irradiation of a trans-anethole toluene solution with UV-Vis at $-5,5$ and $15^{\circ} \mathrm{C}$ for $2 \mathrm{~h}$. In addition to cis-anethole, five other compounds were identified at relative amounts above $0.1 \%$ in all cases. Anethole (cis- and trans-) and their dimers were tentatively identified according to reported data $[9,10]$ and the comparison of their mass spectra (EI, $70 \mathrm{eV}$ ) fragmentation patterns, and calculated dipole moments and ionization potentials (Table 2). The interaction of an $S_{1}$ excited $t-A$ molecule with another one in its ground state, $S_{o}$ in a [2+2] cycloaddition leads to dimers $\mathbf{6 c}$ (anti head-to-head) and $\mathbf{6 e}$ (syn headto-head). The structure of dimer $\mathbf{6 e}$, the most abundant product (peak 7) in the chromatograms (Figure 3), was assigned by Nozaki et al. [21] based on independent synthesis and NMR spectra. This dimer was the only sensitizer-free trans-anethole dimerization $(313 \mathrm{~nm})$ product reported by Lewis and Kojima [9,10]. The mass spectrum of dimer $\mathbf{6 c}$ had been reported by Meyer and Metzger [22]. Dimer 6c (peak 5), the second most-abundant product in the chromatograms (Figure 3), was obtained in Lewis and Kojima's experiments when a sensitizer (1,4-dicyanobenzene, cyanoanthracene) was present. Marquez et al. included dimer $\mathbf{6 c}$ as one of the products of trans-anethole electron transfer reaction with radical cation tri-(4-bromophenyl) ammonium [23]. 
Scheme 3. Proposed mechanism for the formation of singly and doubly deuterated dimers $\mathbf{5 b}$ obtained after the exposure of trans-anethole to deuterated faujasite, HDY.<smiles>C/C=C/c1ccc(OC)cc1</smiles><smiles>[2H][O+](C)c1ccc(/C=C/C)cc1</smiles><smiles>[2H]C([CH+]C)c1ccc(OC)cc1</smiles><smiles>C=Cc1ccccc1OC</smiles><smiles>[2H]/C(=C\C)c1ccc(OC)cc1</smiles><smiles>[2H]C(C)C(c1ccc(OC)cc1)C([CH+]C)(c1ccc(OC)cc1)C(C)C</smiles><smiles>[2H]C(C)C(c1ccc(OC)cc1)C([CH+]C)(c1ccc(OC)cc1)C(C)C</smiles><smiles>CCc1cccc(OC)c1</smiles><smiles>[2H]C(C)Cc1ccc(OC)cc1</smiles><smiles>[2H]C(C)=Cc1ccc(OC)cc1</smiles>

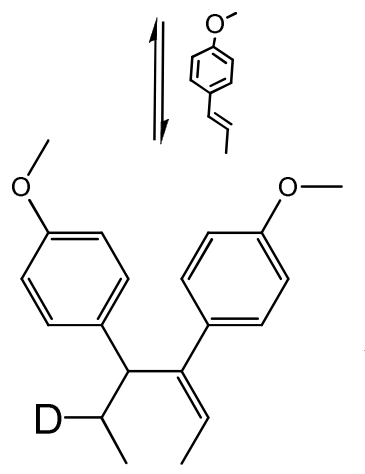<smiles>[2H]C(C)C(c1ccc(OC)cc1)C([C+]C)(c1ccc(I)cc1)c1ccc(OC)cc1</smiles>

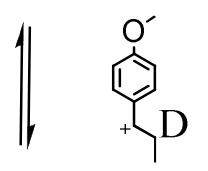

Dimer $5 b, D_{1}$

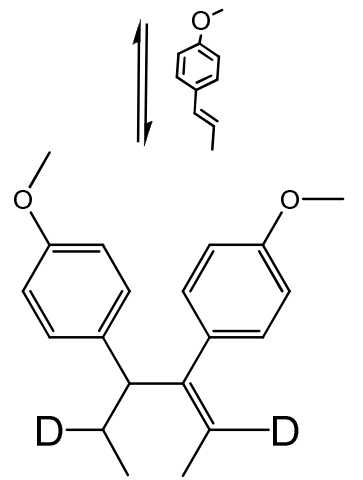

Dimer $5 b, \mathrm{D}_{2}$ 
Figure 3. Chromatographic profiles of the different products obtained during transanethole photoreaction (UV-Vis) in toluene at $-5,5$, and $15{ }^{\circ} \mathrm{C}$ for $2 \mathrm{~h}$. 1. cis-Anethole; 2 . trans-anethole; 3. Dimer 6a; 4. Dimer 6b; 5. Dimer 6c; 6. Dimer 6d; 7. Dimer 6e.
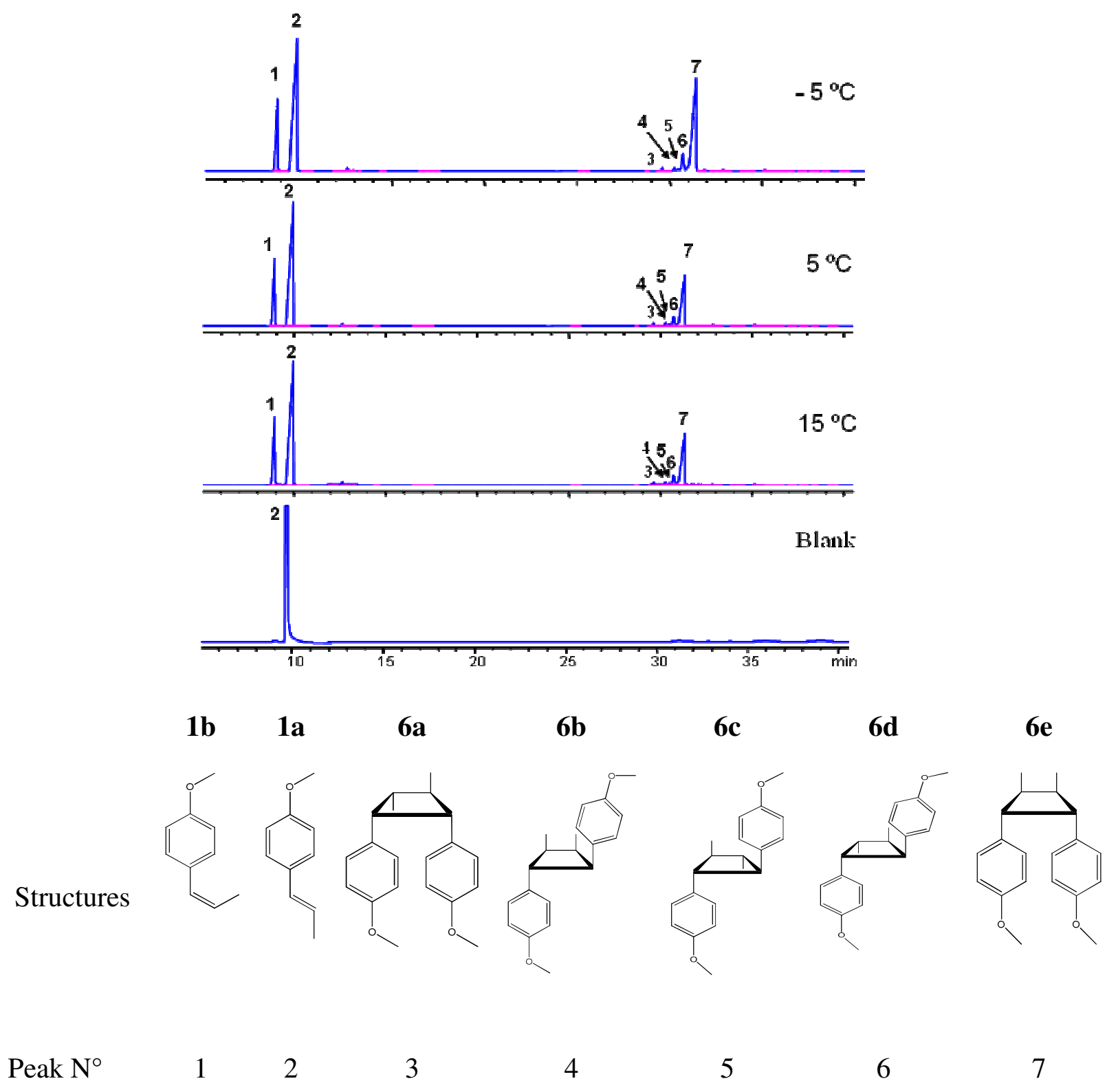

Table 2. Anethole dimers 6a-6e formed during trans-anethole photoreaction.

\begin{tabular}{|c|c|c|c|c|c|c|}
\hline \multirow[b]{2}{*}{ Dimer } & \multirow[b]{2}{*}{$\begin{array}{c}\text { Molecular structure, } \\
\mathrm{R}=p \text {-Methoxy-phenyl }\end{array}$} & \multicolumn{2}{|c|}{ DB-5 column } & \multirow{3}{*}{$\begin{array}{c}\mathrm{t}_{\mathrm{R}}, \min \\
(\text { Polar column, } \\
\text { DB-WAX) }\end{array}$} & \multirow{2}{*}{$\begin{array}{l}\text { Dipole } \\
\text { moment, } \\
\text { Debye }\end{array}$} & \multirow[b]{2}{*}{$\mathrm{EI}(\mathrm{eV})$} \\
\hline & & $\begin{array}{l}t_{R}, \min \\
\text { (Fig. 3) }\end{array}$ & RI & & & \\
\hline $\mathbf{6 a}$ & & 29.6 & 2139 & & 2.11 & 7.90 \\
\hline
\end{tabular}


Table 2. Cont.

6b

Dimers 6a, 6b and $\mathbf{6 d}$ have been found among cis-anethole photodimerization (at $313 \mathrm{~nm}$ ) products, but not among trans-anethole irradiation products, formed in the presence or absence of sensitizer $[10,24]$. Their formation during trans-anethole UV-Vis irradiation may be explained by the reaction of cis-anethole formed during the experiment. Figure 4 shows a continuous increase of cis-anethole concentration during the experiment $(2 \mathrm{~h})$ at the three temperatures employed. The relative amounts of $\mathbf{6 a}, \mathbf{6 b}$ and $\mathbf{6 d}$ dimers showed a small increase. Thus, we conclude that the rate of trans-anethole photoisomerization is higher than that of cis-anethole photodimerization. Dimer 6d formation was linked in Lewis and Kojima's work with oxygen sensitization of trans-anethole. In the present work, trans-anethole UV-Vis irradiation experiments were conducted in a sealed reactor that had been maintained under dry nitrogen flow to remove molecular oxygen. No epoxides were found among the UV-Vis irradiation products. The scheme of formation proposed for the various photodimerization products is shown in Scheme 4.

Caldwell et al. [24] observed cis-anethole configuration retention in [2+2] reactions with singlet 9-cyanophenanthrene. The dimer structures proposed here maintain the cis-anethole stereochemistry. Dimerizations result from ${ }^{1} t-\mathrm{A}^{*_{-}}{ }^{1} t-\mathrm{A}$, and to a lesser extent, from ${ }^{1} t$ - $*_{-}{ }^{1} c$-A interactions. The latter happens with lower frequency due to the low cis-anethole concentration. Table 3 presents conversions and selectivities determined after UV-Vis trans-anethole toluene solution irradiation for $2 \mathrm{~h}$ at $-5,5$ and $15{ }^{\circ} \mathrm{C}$. cis-Anethole and dimer $6 \mathrm{e}$ were the most abundant products. While trans-anethole conversion increased with temperature, the selectivity towards cis-anethole decreased, whereas those 
of $\mathbf{6 c}$ and $\mathbf{6 e}$ dimers increased. This shows the competition that exists between isomerization and dimerization.

Figure 4. Variation of cis-anethole concentration during trans-anethole UV-Vis iiradiation.

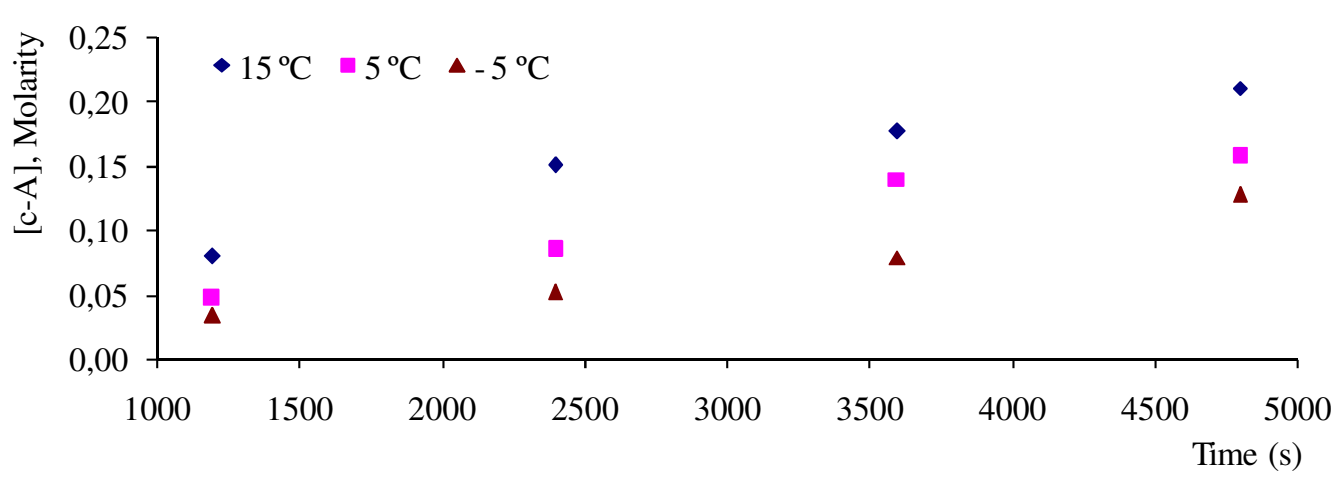

Table 3. Conversion and selectivities of trans-anethole (in toluene) photoreaction products (UV-Vis, $120 \mathrm{~min},-5,5$ and $15^{\circ} \mathrm{C}$ ).

\begin{tabular}{|c|c|c|c|c|c|c|c|}
\hline \multirow{2}{*}{$\mathrm{T}^{\circ} \mathrm{C}$} & \multirow{2}{*}{$\begin{array}{l}\text { trans- Anethole } \\
\text { conversion, \% }\end{array}$} & \multicolumn{6}{|c|}{ Selectivity, \% } \\
\hline & & cis-anethole & $\mathbf{6 a}$ & $\mathbf{6 b}$ & $6 c$ & 6d & $6 e$ \\
\hline-5 & 30 & 42 & $<1$ & 2 & 5 & 1 & 50 \\
\hline 5 & 35 & 38 & $<1$ & 2 & 5 & 2 & 54 \\
\hline 15 & 52 & 34 & $<1$ & $<1$ & 8 & 1 & 57 \\
\hline
\end{tabular}

Scheme 4. Scheme proposed for trans-anethole photodimerization products.

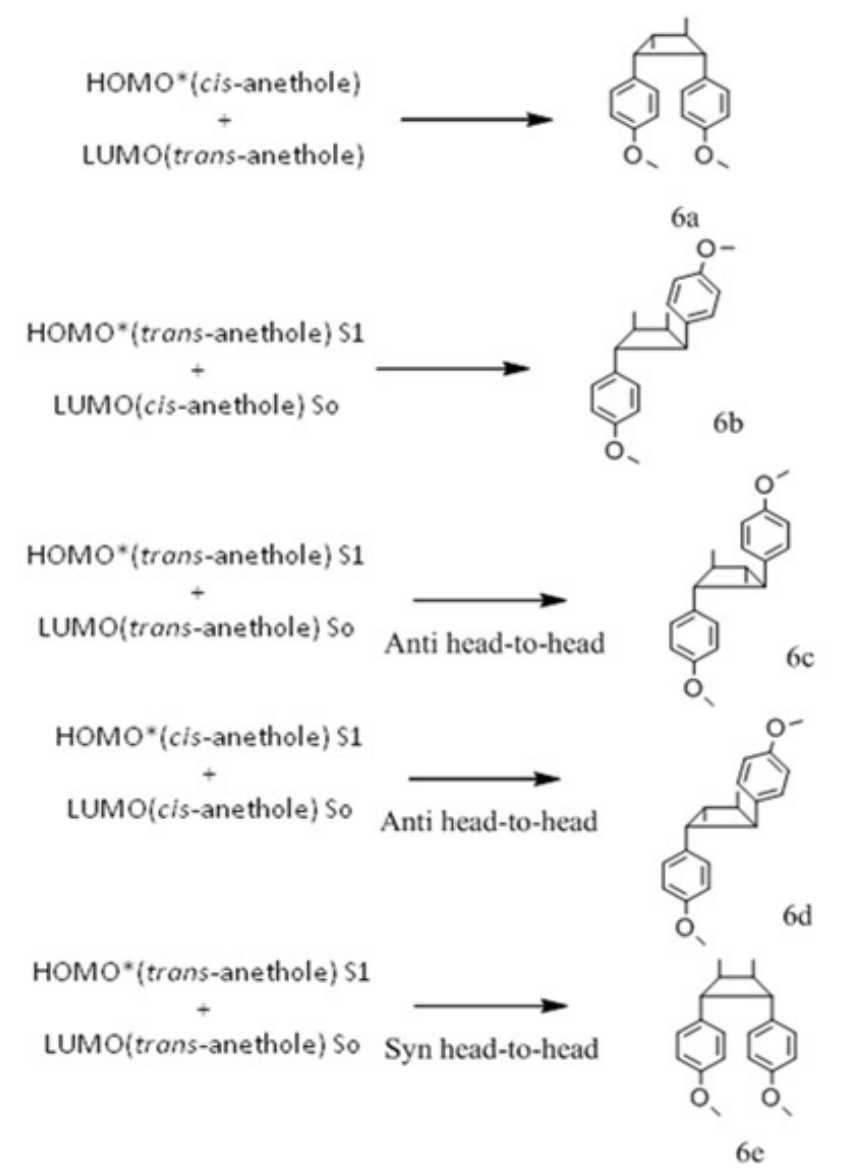




\subsection{Quantum yield of trans-anethole photoisomerization}

Quantum yields of the formation of cis-anethole $\left(\Phi_{1 a \rightarrow 1 b}\right)$ and $\mathbf{6 c}\left(\Phi_{1 a \rightarrow 2 c}\right)$ and $\mathbf{6 e}\left(\Phi_{1 a \rightarrow 2 e}\right)$ dimers at $-5,5$ and $15{ }^{\circ} \mathrm{C}$, were calculated as the ratio of reaction rate over flux of absorbed photons (Table 4). In each case, the reaction rate was calculated as the slope of the plot of concentration Vs time. Figures 4 and 5 show the linear nature of the concentration profiles of cis-anethole and dimers $\mathbf{6 c}$ and $\mathbf{6 e}$. Potassium ferrioxalate solutions were employed in the actinometric determination of flux as $3 \times 10^{-4} \pm$ $2 \times 10^{-5}$ mol photon $\mathrm{L}^{-1} \mathrm{~s}^{-1}$.

Figure 5. Concentration profiles of dimers $\mathbf{6 c}$ and $\mathbf{6 e}$ during trans-anethole UV-Vis irradiation for $2 \mathrm{~h}$.

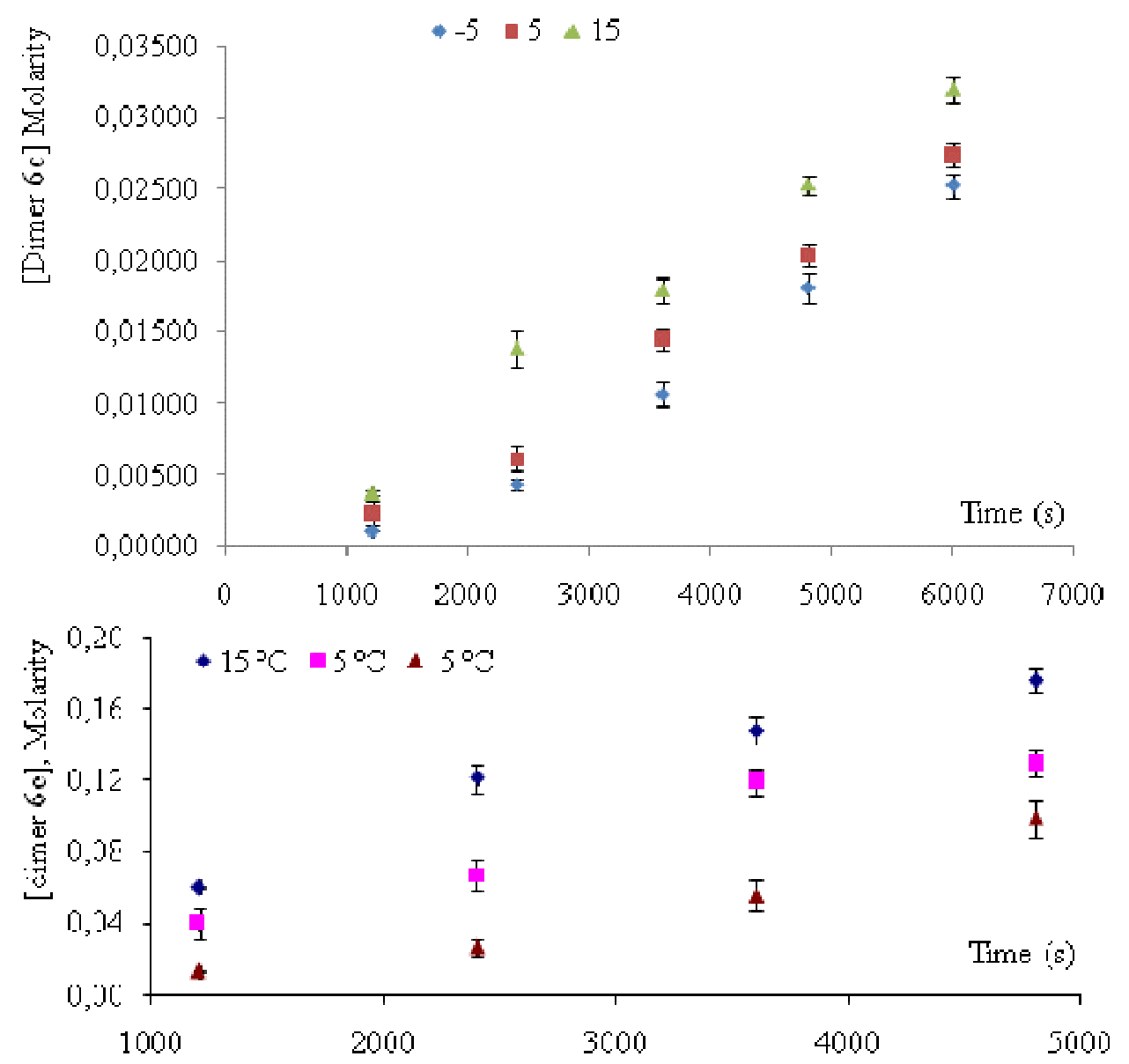

Table 4. Quantum yields determined for trans-anethole isomerization and dimerization.

\begin{tabular}{cccc}
\hline $\mathbf{T}\left({ }^{\mathbf{o}} \mathbf{C}\right)$ & $\begin{array}{c}\text { cis-Anethole } \\
\mathbf{a} \Phi_{1 a \rightarrow 1 b}\end{array}$ & $\begin{array}{c}\text { 6c Dimer } \\
{ }^{\mathbf{b}} \Phi_{1 a \rightarrow 2 c} \times \mathbf{1 0}^{\mathbf{6}}\end{array}$ & $\begin{array}{c}\text { 6e Dimer } \\
{ }^{\mathbf{c}} \Phi_{1 a \rightarrow 2 e}\end{array}$ \\
\hline-5 & 0.09 & 6 & 0.08 \\
+5 & 0.11 & 5 & 0.09 \\
+15 & 0.12 & 5 & 0.10 \\
\hline
\end{tabular}

${ }^{\mathrm{a}} \mathrm{CV}(\%)=1.1 \% ;{ }^{\mathrm{b}} \mathrm{CV}(\%)=1.6 \% ;{ }^{\mathrm{c}} \mathrm{CV}(\%)=1.2 \% ; \mathrm{n}=3$ 
The monotonous increase of trans-anethole photoisomerization and dimerization products (Figures 4 and 5) is consistent with a higher rate for the reaction of excited singlet trans-anethole $\left({ }^{1} t\right.$-A* $)$ with trans-anethole than that observed for its reaction with $c i s$-anethole. Since cis-anethole is being formed, encounters of ${ }^{1} t$-A* with $c i s$-anethole are much less likely than those with trans-anethole. Additionally, cis-anethole has been reported as less reactive than trans-anethole in the photocycloaddition with 9cyanophenanthrene and 6-methylphenantridine [24]. The much higher abundance of $\mathbf{6 c}$ and $\mathbf{6 e}$ dimers in comparison with $\mathbf{6 a}$ and $\mathbf{6} \mathbf{b}$ dimers is another consequence of this reaction rate difference.

The quantum yields obtained (Table 4) are close to those reported for trans-anethole photoisomerization in hexane and acetonitrile $\left(\Phi_{1 a \rightarrow b b}=0.12\right.$ and 0.13 , respectively) [26]. The increase of quantum yields with temperature indicates the existence of an energy barrier in photoisomerization and photodimerization. The $\Phi_{1 a \rightarrow 1 b}$ values determined after multichromatic UV-Vis irradiation of trans-anethole in toluene $(0.35 \mathrm{M})$ are similar to the values reported for trans-anethole photoisomerization after monochromatic $(254,281$, or $313 \mathrm{~nm})$ irradiation $[9,10]$. Thus, there is no appreciable dependence of quantum yield on excitation wavelength. The quantum yield for transretinal photoisomerization $\left(\Phi_{t \rightarrow c} \sim 0.67\right.$ ) has been found to be independent of excitation wavelength [25]. On the other hand, conformational photoisomerization [26] of trans-stilbene and stilbene derivatives [27], some fluorinated compounds [28], and azobenzene and its dimers [29-34] has been reported as irradiation wavelength dependent.

\section{Experimental}

\subsection{General}

trans-Anethole (99\%), ammonium nitrate (98\%) $\mathrm{D}_{2} \mathrm{O}$ (99.96\% deuteration), NaY zeolite, were obtained from Aldrich Chemical Co. Inc (Milwaukee, WI, USA). Toluene (99\%, reagent grade) and $\mathrm{DCl}$ (20\% in $\mathrm{D}_{2} \mathrm{O}, 99.5 \%$ deuteration) were purchased from Merck (Darmstadt, Germany). cisAnethole chromatographic reference data were obtained from hydrodistilled anise seed essential oil. $\mathrm{HCl}$ (ACS grade, 37\%) was obtained from J. T. Baker (Phillipsburg, NJ, USA).

Chromatographic quantification was performed with an HP 5890A Series II (Hewlett-Packard, Palo Alto, CA, USA) gas chromatograph equipped with a split/splitless injection system (split ratio 6:1), a flame ionization detector (FID) and a DB-5 (J\&W Scientific, Folsom, CA, USA) capillary column $(30 \mathrm{~m} \times 0.32 \mathrm{~mm} \times 0.25 \mu \mathrm{m})$ coated with $5 \%$-phenyl-poly(methylsiloxane). Synthetic air (zero grade), $\mathrm{H}_{2}(99.995 \%), \mathrm{N}_{2}(99.995 \%)$, and $\mathrm{He}(99.995 \%)$, were obtained from Aga-Fano S.A. (Bucaramanga, Colombia). The oven temperature was programmed from $80{ }^{\circ} \mathrm{C}(1 \mathrm{~min}) @ 10{ }^{\circ} \mathrm{C} / \mathrm{min}$ to $230{ }^{\circ} \mathrm{C}$ ( $5 \mathrm{~min}$ ). The injection port and detector temperatures were maintained at 250 and $280{ }^{\circ} \mathrm{C}$, respectively. Chromatographic data were processed with HP ChemStation A.06.03 (Hewlett-Packard, Palo Alto, CA, USA) software.

Two GC-MS systems were employed: an Agilent Technologies 6890 Plus gas chromatograph (Palo Alto, CA) equipped with an Agilent Technologies 5973N mass selective detector (EI, $70 \mathrm{eV}$, $m / z$ 40-350) and an Agilent Technologies 6890 gas chromatograph coupled to an Agilent Technologies 5975 mass selective detector (EI, $70 \mathrm{eV}, \mathrm{m} / \mathrm{z}$ 40-350). Both systems were equipped with a split/splitless injector (split ratio 1:30), a 7863 automatic injector and an MS-ChemStation G1701- 
DA data system that included the spectral libraries WILEY 138K, NIST 2002, and QUADLIB 2004. A fused-silica 5\% phenylpoly(dimethylsiloxane) capillary column (DB-5MS, J\&W Scientific) of $60 \mathrm{~m}$, $0.25 \mathrm{~mm}$ i.d., $0.25 \mu \mathrm{m}, \mathrm{d}_{\mathrm{f}}$, and a fused-silica cross-linked, bonded poly(ethylene glycol) capillary column (DB-WAX, J \& W Scientific, Folsom, CA, USA) of $60 \mathrm{~m}, 0.25 \mathrm{~mm}$, i.d. $0.25 \mu \mathrm{m}$, $\mathrm{d}_{\mathrm{f}}$, were employed. The oven temperature program employed with the DB-5MS column was from $100{ }^{\circ} \mathrm{C}(3$ min) to $200{ }^{\circ} \mathrm{C}(5 \mathrm{~min})$ at $10{ }^{\circ} \mathrm{C} / \mathrm{min}$, then to $280{ }^{\circ} \mathrm{C}(40 \mathrm{~min})$ at $15^{\circ} \mathrm{C} / \mathrm{min}$. For the DB-WAX column, the oven temperature was programmed from $100{ }^{\circ} \mathrm{C}(3 \mathrm{~min})$ to $200{ }^{\circ} \mathrm{C}(5 \mathrm{~min})$ at $10{ }^{\circ} \mathrm{C} / \mathrm{min}$, then to $220{ }^{\circ} \mathrm{C}(40 \mathrm{~min})$ at $4{ }^{\circ} \mathrm{C} / \mathrm{min}$. The ionization chamber and the transfer line temperatures were kept at $230{ }^{\circ} \mathrm{C}$ and $285{ }^{\circ} \mathrm{C}$, respectively. The following are the mass spectral data of the various dimers encountered as trans-anethole photoreaction products.

(Z)-1,4-bis(4-Methoxyphenyl)-2,3-dimethylbut-1-ene (2a). $\mathrm{W}_{\mathrm{M}+} \cdot(4.8 \%) . \mathrm{m} / z$ (I\%): $\mathrm{M}^{+} \cdot 296(12)$, [M$\left.\mathrm{C}_{10} \mathrm{H}_{12} \mathrm{O}\right]^{+}$267(7), [M- $\left.\mathrm{C}_{2} \mathrm{H}_{5}-\mathrm{C}_{7} \mathrm{H}_{8} \mathrm{O}\right]^{+}$159(28), [M- $\left.\mathrm{C}_{12} \mathrm{H}_{15} \mathrm{O}\right]^{+}$121(100).

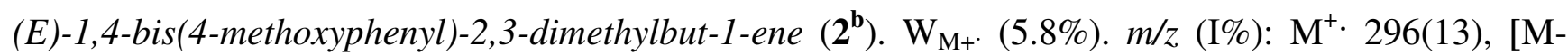
$\left.\mathrm{C}_{2} \mathrm{H}_{5}\right]^{+}$267(5), [M- $\left.\mathrm{C}_{2} \mathrm{H}_{5}-\mathrm{C}_{7} \mathrm{H}_{8} \mathrm{O}\right]^{+}$159(24), [M-C $\left.{ }_{10} \mathrm{H}_{12} \mathrm{O}\right]^{+}$148(1), [M- $\left.\mathrm{C}_{12} \mathrm{H}_{15} \mathrm{O}\right]^{+}$121(100).

(Z)-3,5-bis(4-methoxyphenyl)-4-methylpent-2-ene $\left(3^{\mathbf{a}}\right) . \mathrm{W}_{\mathrm{M}+} \cdot(1.7 \%) . \mathrm{m} / z$ (I\%): $\mathrm{M}^{+} \cdot 296(4),\left[\mathrm{M}_{-} \mathrm{C}_{2} \mathrm{H}_{5^{-}}\right.$ $\left.\mathrm{C}_{7} \mathrm{H}_{8} \mathrm{O}\right]^{+}$159(2), [M- $\left.\mathrm{C}_{10} \mathrm{H}_{12} \mathrm{O}\right]^{+}$148(100), [M- $\left.\mathrm{C}_{12} \mathrm{H}_{15} \mathrm{O}\right]^{+}$121(38).

(E)-3,5-bis(4-methoxyphenyl)-4-methylpent-2-ene $\left(3^{\mathbf{b}}\right) . \mathrm{W}_{\mathrm{M}+} \cdot(1.3 \%) . \mathrm{m} / \mathrm{z}(\mathrm{I} \%): \mathrm{M}^{+} \cdot 296(3),\left[\mathrm{M}_{-} \mathrm{C}_{2} \mathrm{H}_{5^{-}}\right.$ $\left.\mathrm{C}_{7} \mathrm{H}_{8} \mathrm{O}\right]^{+}$159(3), [M- $\left.\mathrm{C}_{10} \mathrm{H}_{12} \mathrm{O}\right]^{+}$148(100), [M- $\left.\mathrm{C}_{12} \mathrm{H}_{15} \mathrm{O}\right]^{+}$121(34).

(E)-1,3-bis(4-methoxyphenyl)-2-methylpent-1-ene $\left(4^{\mathrm{a}}\right) . \mathrm{W}_{\mathrm{M}_{+}} \cdot(7.6 \%) . \mathrm{m} / \mathrm{z}(\mathrm{I} \%): \mathrm{M}^{+} \cdot 296(28)$, [M$\left.\mathrm{C}_{2} \mathrm{H}_{5}\right]^{+}$267(100), [M-C $\left.\mathrm{C}_{2} \mathrm{H}_{5}-\mathrm{C}_{7} \mathrm{H}_{8} \mathrm{O}\right]^{+} 159(28)$, [M- $\left.\mathrm{C}_{10} \mathrm{H}_{12} \mathrm{O}\right]^{+} 148(2),\left[\mathrm{M}-\mathrm{C}_{12} \mathrm{H}_{15} \mathrm{O}\right]^{+}$121(17).

(Z)-1,3-bis(4-methoxyphenyl)-2-methylpent-1-ene $\left(\mathbf{4}^{\mathbf{b}}\right) . \mathrm{W}_{\mathrm{M}+} \cdot(5.0 \%) \cdot \mathrm{m} / \mathrm{z}(\mathrm{I} \%): \mathrm{M}^{+} \cdot 296(24)$, [M$\left.\mathrm{C}_{2} \mathrm{H}_{5}\right]^{+}$267(100), [M-C $\left.\mathrm{C}_{2} \mathrm{H}_{5}-\mathrm{C}_{7} \mathrm{H}_{8} \mathrm{O}\right]^{+}$159(31), [M- $\left.\mathrm{C}_{10} \mathrm{H}_{12} \mathrm{O}\right]^{+}$148(1), [M- $\left.\mathrm{C}_{12} \mathrm{H}_{15} \mathrm{O}\right]^{+}$121(19).

(Z)-3,4-bis(4-methoxyphenyl)hex-2-ene $\quad\left(\mathbf{5}^{\mathbf{a}}\right) . \quad \mathrm{W}_{\mathrm{M}+} \cdot(6.5 \%) . \quad m / z \quad(\mathrm{I} \%): \quad \mathrm{M}^{+} \cdot \quad 296(34), \quad\left[\mathrm{M}_{-} \mathrm{C}_{2} \mathrm{H}_{5}\right]^{+}$ 267(100), [M- $\left.\mathrm{C}_{2} \mathrm{H}_{5}-\mathrm{C}_{7} \mathrm{H}_{8} \mathrm{O}\right]^{+}$159(82), [M- $\left.\mathrm{C}_{12} \mathrm{H}_{15} \mathrm{O}\right]^{+}$121(42).

(E)-3,4-bis(4-methoxyphenyl)hex-2-ene $\quad\left(\mathbf{5}^{\mathbf{b}}\right) . \quad \mathrm{W}_{\mathrm{M}+} \cdot(5.2 \%) . \quad \mathrm{m} / \mathrm{z} \quad(\mathrm{I} \%): \quad \mathrm{M}^{+} \cdot \quad 296(28), \quad\left[\mathrm{M}_{-} \mathrm{C}_{2} \mathrm{H}_{5}\right]^{+}$ 267(100), [M- $\left.\mathrm{C}_{2} \mathrm{H}_{5}-\mathrm{C}_{7} \mathrm{H}_{8} \mathrm{O}\right]^{+}$159(98), [M-C $\left.{ }_{10} \mathrm{H}_{12} \mathrm{O}\right]^{+}$148(3), [M- $\left.\mathrm{C}_{12} \mathrm{H}_{15} \mathrm{O}\right]^{+}$121(30).

(1a,2a,3a,4b)-1,2-bis(4-methoxyphenyl)-3,4-dimethylcyclobutane $\left(\mathbf{6}^{\mathrm{a}}\right) . \mathrm{W}_{\mathrm{M}+} \cdot(6.6 \%) . \mathrm{m} / \mathrm{z}(\mathrm{I} \%): \mathrm{M}^{+}$.

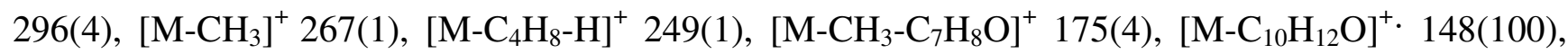
$\left[\mathrm{M}-\mathrm{C}_{12} \mathrm{H}_{15} \mathrm{O}\right]^{+}$121(12).

(1a,2b,3a,4a)-1,2-bis(4-methoxyphenyl)-3,4-dimethylcyclobutane $\left(\mathbf{6}^{\mathbf{b}}\right) . \mathrm{W}_{\mathrm{M}_{+} \cdot(4.7 \%) .} \mathrm{m} / \mathrm{z}(\mathrm{I} \%): \mathrm{M}^{+}$. 296(81), [M-CH$]^{+}$267(9), [M- $\left.\mathrm{C}_{4} \mathrm{H}_{8}-\mathrm{H}\right]^{+}$249(15), [M- $\left.\mathrm{CH}_{3}-\mathrm{C}_{7} \mathrm{H}_{8} \mathrm{O}\right]^{+}$175(36), [M- $\left.\mathrm{C}_{10} \mathrm{H}_{12} \mathrm{O}\right]^{+} \cdot 148(67)$, $\left[\mathrm{M}-\mathrm{C}_{12} \mathrm{H}_{15} \mathrm{O}\right]^{+}$121(100).

(1a,2b,3a,4b)-1,2-bis(4-methoxyphenyl)-3,4-dimethylcyclobutane $\left(\mathbf{6}^{\mathbf{c}}\right) . \mathrm{W}_{\mathrm{M}^{+}}(0.6 \%) . \mathrm{m} / \mathrm{z}(\mathrm{I} \%): \mathrm{M}^{+}$. $296(<1),\left[\mathrm{M}-\mathrm{C}_{10} \mathrm{H}_{12} \mathrm{O}\right]^{+} \cdot 148(100),\left[\mathrm{M}-\mathrm{C}_{12} \mathrm{H}_{15} \mathrm{O}\right]^{+}$121(4). 
(1a,2b,3b,4a)-1,2-bis(4-methoxyphenyl)-3,4-dimethylcyclobutane $\left(\mathbf{6}^{\mathbf{d}}\right) . \mathrm{W}_{\mathrm{M}_{+}} \cdot(1.2 \%) . \mathrm{m} / \mathrm{z}(\mathrm{I} \%): \mathrm{M}^{+}$. 296(88), $\left[\mathrm{M}-\mathrm{CH}_{3}\right]^{+}$267(8), [M-C $\left.\mathrm{C}_{4} \mathrm{H}_{8}-\mathrm{H}\right]^{+}$249(9), [M- $\left.\mathrm{CH}_{3}-\mathrm{C}_{7} \mathrm{H}_{8} \mathrm{O}\right]^{+}$175(38), [M-C $\left.\mathrm{C}_{10} \mathrm{H}_{12} \mathrm{O}\right]^{+} \cdot 148(34)$, $\left[\mathrm{M}-\mathrm{C}_{12} \mathrm{H}_{15} \mathrm{O}\right]^{+} 121(100)$.

(1a,2a,3b,4b)-1,2-bis(4-methoxyphenyl)-3,4-dimethylcyclobutane $\left(\mathbf{6}^{\mathrm{e}}\right) . \mathrm{W}_{\mathrm{M}+}(0.5 \%) . \mathrm{m} / \mathrm{z}(\mathrm{I} \%)$ : $\mathrm{M}^{+}$. 296(<1), [M-C $\left.\mathrm{C}_{10} \mathrm{H}_{12} \mathrm{O}\right]^{+} \cdot 148(100)$, [M- $\left.\mathrm{C}_{12} \mathrm{H}_{15} \mathrm{O}\right]^{+}$121(4).

\subsection{Faujasite preparation and characterization}

$\mathrm{NaY}$ zeolite $(10 \mathrm{~g})$ was suspended at $60^{\circ} \mathrm{C}$ for $2 \mathrm{~h}$ in an aqueous ammonium nitrate solution (1M, $150 \mathrm{~mL})$ under continuous stirring $(1,000 \mathrm{rpm})$. It was dried afterwards $\left(100{ }^{\circ} \mathrm{C}, 12 \mathrm{~h}\right)$ and placed in a quartz tube ( $1 \mathrm{~cm}$ I.D.) in a cylindrical oven and heated to $550{ }^{\circ} \mathrm{C}$ under a steam flow at 1.38 bar. Heating periods of 2, 4 and $6 \mathrm{~h}$ led to the formation of zeolite samples HY1, HY2 and HY3, respectively. They were subsequently treated with $\mathrm{HCl}(0.5 \mathrm{M}, 6 \mathrm{~h}$, continuous stirring $)$ to remove extra-framework aluminum.

\subsection{Zeolite characterization}

Dealuminated HY zeolites were characterized by means of elemental analysis (energy dispersive X-ray fluorescence, Shimadzu EDX 800 HS; Columbia, MD, USA), infrared spectroscopy (Bruker, Tensor 27; Billerica, MA, USA) and X-ray diffraction (Rigaku D-MAX-III/B; Tokyo, Japan).

\section{4. trans-Anethole treatment with dealuminated HY zeolites}

trans-Anethole toluene solutions $(2 \mathrm{~mL}, 0,1 \mathrm{M})$ were placed into three screw-capped test tubes $(10$ $\mathrm{mL}$ ), each one containing a different zeolite (zeolites HY1, HY2 and HY3, $25 \mathrm{mg}$ ). Zeolites had been previously activated $\left(100{ }^{\circ} \mathrm{C}, 12 \mathrm{~h}\right)$. Reactions were performed by heating the tubes in a water bath (30, 60 and $90{ }^{\circ} \mathrm{C}, 5 \mathrm{~h}$ ). After chromatographic analysis of the resultant mixtures, conversion and selectivities were calculated as follows:

$$
\begin{gathered}
\% \text { Conversion, } t-\text { anethole }=100 \times \frac{\llbracket t-\text { anethole } \rrbracket_{\text {initial }}-\llbracket t-\text { anethole } \rrbracket_{\text {final }}}{\llbracket t-\text { anethole } \rrbracket_{\text {initial }}} \text { (2) } \\
\% \text { Selectivity }=100 \times \frac{\llbracket \text { product } \rrbracket_{\text {formed }}}{\llbracket t-\text { anethole } \rrbracket_{\text {consumed }}} \text { (3) }
\end{gathered}
$$

Molecular ion stabilities, $\mathrm{W}_{\mathrm{M}+}$, were calculated from the dimers' mass spectra and used to distinguish configuration isomers: according to equation 4 , the molecular ion abundance is divided by the sum of abundances of all fragment ions $>m / z$. 50:

$$
W_{M+\cdot}=100 \times \frac{I_{M+\cdot}}{\sum_{50} I_{\text {Fragment ions }}}(4)
$$

\section{5. trans-Anethole treatment with deuterated HY zeolite}

Zeolite F1 (10 mg) was suspended in $\mathrm{DCl} / \mathrm{D}_{2} \mathrm{O}(1: 9,1 \mathrm{~mL})$ and heated to $60{ }^{\circ} \mathrm{C}$ for $6 \mathrm{~h}$. It was then vacuum filtered and dried $\left(100{ }^{\circ} \mathrm{C}, 12 \mathrm{~h}\right)$. An infrared spectrum of the resulting material was acquired 
(Bruker Tensor FT-IR spectrometer). This zeolite sample was then suspended in a test tube (screw cap, $10 \mathrm{~mL})$ with a trans-anethole toluene solution $(0,1 \mathrm{M}, 2 \mathrm{~mL})$ and heated to $60{ }^{\circ} \mathrm{C}$ for $5 \mathrm{~h}$ under continuous stirring. The tube was filled under dry nitrogen flow. The mixture was decanted and analyzed by GC-MS in selected ion monitoring mode (SIM). The selected ions corresponded to the molecular ion and its main fragments, together with their deuterated analogs $(\mathrm{m} / \mathrm{z} 148,149,117,118$, $133,134)$.

\subsection{Phototransformation kinetics}

A trans-anethole toluene solution $(0.35 \mathrm{M}, 15 \mathrm{~mL})$ was irradiated in an Ace Glass (Vineland, NJ, USA) 7880 photoreactor assembly with a 5.5 Watt Pen-Ray gaseous Hg discharge UV-Vis lamp, at $5{ }^{\circ} \mathrm{C}$ for $120 \mathrm{~min}$ under constant stirring (100 rpm). trans-Anethole toluene solution aliquots $(10 \mu \mathrm{L})$ were withdrawn every $20 \mathrm{~min}$ and analyzed by GC-FID, using the external standard (trans-anethole) method for quantification.

\subsection{Quantum yield determination}

The Pen Ray UV lamp emission spectra were recorded with a high resolution HRG000c6-UV-NIR spectrometer (Ocean Optics, Dunedin, FL, USA) at the Atomic and Molecular Spectroscopy Laboratory of the Industrial University of Santander (Colombia). Discrete emission lines were found at 255, 313, 366, 405, 437, 548, and $579 \mathrm{~nm}$. Quantum yields were determined as the quotient between the time derivative of the concentration and the flux, according to the following equation, in which $\mathrm{X}$ stands for cis-anethole, dimer $\mathbf{2 c}$, or dimer $\mathbf{2 e}$ :

$$
\Phi_{1 a \rightarrow X}=\frac{d \llbracket X \rrbracket / d t}{I_{a}}
$$

Potassium ferrioxalate was used for the actinometric determination of Ia, the number of quanta absorbed by trans-anethole per unit concentration, per unit time, according to the IUPAC recommended procedure [35].

\section{Conclusions}

Isomerization and dimerization are concurrent processes in the trans-anethole transformation observed during its exposure to acid sites in a zeolite or UV-Vis irradiation. Proton transfer from the zeolite to trans-anethole generates cationic intermediaries which lead the formation of eight different anethole dimers (methoxyphenyl-disubstituted hexenes). Their relative amounts agreed with those expected from the relative stability of the intermediary cationic species. The use of deuterated zeolites showed that the proton eliminated during the isomerization process is not necessarily the same proton transferred to the trans-anethole molecule when the cationic intermediary is formed. cis-Anethole and five isomeric methoxyphenyl-disubstituted cyclobutanes were observed as products of the transformation induced by the UV-Vis irradiation of trans-anethole. 


\section{Acknowledgements}

Financial support from Colciencias (Grant RC-432-2004) is gratefully acknowledged. The collaboration and guidance of Jose Antonio Henao and Olger Mendoza, M. Sc., in the X-ray diffraction and fluorescence experiments are acknowledged, as well as the oven loan from the Condensed Materials Laboratory of Jorge Martínez.

\section{References}

1. Leung, A.Y.; Foster, S. Encyclopedia of Common Natural Ingredients: Used in Food, Drugs, and Cosmetics, 2nd ed.; John Wiley \& Sons: Hoboken, NJ, USA, 2003; pp. 36-38.

2. Pareck, S.K.; Trivedi, K.C.; Maheshwari, S.K.; Gangarade, S.K.; Gangarade, S.K.; Masheshwari, M.L.; Gupta, R. Studies on cultivation of anise in India. Indian Perfum. 1980, 24, 88-92.

3. Cosentino, C.I.G.; Tuberodo, B.; Pisano, M.; Satta, V.; Mascia, E.; Palmas, F. In-vitro antimicrobial activity and chemical composition of sardinian Thymus essential oils. Lett. Appl. Microbiol. 1999, 29, 130-135.

4. Newberne, P.; Smith, R.L.; Doull, J.; Goodman, J.I.; Munro, I.C.; Portoghese, P.S.; Wagner, B.M.; Weil, C.S.; Woods, L.A.; Adams, T.B.; Lucas, C.D.; Ford, R.A. The FEMA GRAS assessment of trans-anethole used as a flavoring substance. Food Chem. Toxicol. 1999, 37, 787-811.

5. Smith, R.L.; Cohen, S.M.; Doull, J.; Feron, V.J.; Goodman, J.I.; Marnett, L.J.; Munro, I.C.; Portoghese, P.S.; Waddell, W.J.; Wagner, B.M.; Adams, T.B. Criteria for the safety evaluation of flavoring substances the expert panel of the flavor and extract manufacturers association. Food Chem. Toxicol. 2005, 43, 1141-1177.

6. Stashenko, E.E.; Martínez, C.R.; Martínez, J.R.; Shibamoto, T. Catalytic transformation of anise oil (Pimpinella anisum L.) over zeolite Y. J. High. Resolut. Chromatogr. 1995, 18, 501-503.

7. Biaglow A.I.; Parrillo D.J.; Kokotailo G.T.; Gorte R.J. A study of dealuminated faujasites. J. Catal. 1994, 148, 213-223.

8. Weitkamp, J.; Puppe, L. Catalysis and Zeolites: Fundamentals and Applications; Springer: Heidelberg, Germany, 1999; p. 564.

9. Lewis, F.D.; Kojima, M. Electron transfer induced photoisomerization, dimerization and oxygenation of trans-and-cis-anethole. The role of monomer and dimer cation radicals. J. Am. Chem. Soc. 1988, 110, 8664-8670.

10. Lewis, F.D.; Kojima, M. Photodimerization of singlet trans-and-cis-anethole. Concerted or stepwise? J. Am. Chem. Soc. 1988, 110, 8660-8664.

11. Anand, P.; Maya, G; Tewari, S.C; Rastogi, S.N; Roy, S.K. Biological profile of 1,2-diethyl-1,3bis-(p-methoxyphenyl)-1-propene-A new oral non-steroidal contraceptive. Indian J. Exp. Biol. 1980, 18, 557-560.

12. Wessely, I.F.; Kerschbaum, E.; Kleedorfer, A.; Prillinger, F.; Zajic, E. Synthetic estrogens. Monatsh. Chem. 1940, 73, 127-158. 
13. Whitmore, F.C. Mechanism of the polymerization of olefins by acid catalysts. Ind. Eng. Chem. 1934, 26, 94-95.

14. Tung, S.E.; Mc. Ininch, E. Zeolitic aluminosilicate: I. Surface ionic diffusion, dynamic field, and catalytic activity with hexane on CaY. J. Catal. 1968, 10, 166-174.

15. Docquir, F.; Norberg, V.; Toufar, H.; Paillaud, J.-L.; Su, B.L. Infrared study on the adsorption behavior of methylamine in a series of large pore cationic zeolites. A further confirmation of three types of interaction between methylamine and zeolites. Langmuir 2002, 18, 5963-5966.

16. Janin, A.; Maache, M.; Lavalley, J.C.; Joly, J.F.; Raatz, F.; Szydlowski, N. FT IR study of the silanol groups in dealuminated HY zeolites-nature of the extraframework debris. Zeolites 1991, 11, 391-393.

17. Corma, A.; Planelles, J.; Sánchez-Marin, J.; Tomás, F. The nature of acids sites on fluorinated v$\mathrm{Al}_{2} \mathrm{O}_{3}$. J. Catal. 1985, 92, 284-287.

18. Corma, A. Inorganic solid acids and their use in acid-catalyzed hydrocarbon reactions. Chem. Rev. 1995, 95, 559-614.

19. Haw, J.F.; Richardson, B.R.; Oshiro, I.S.; Lazo, N.D.; Speed, J.A. Reactions of propene on zeolite HY catalyst studied by in situ variable temperature solid-state nuclear magnetic resonance spectroscopy. J. Am. Chem. Soc. 1989, 111, 2052-2058.

20. Richardson, B.R.; Lazo, N.D.; Schettler, P.D.; White, J.L.; Haw, J.F. Reactions of butadiene in zeolite catalyst by in situ variable-temperature solid-state nuclear magnetic resonance spectrometry. J. Am. Chem. Soc. 1990, 112, 2886-2891.

21. Nozaki, H.; Otani, I.; Noyori, R.; Kawanisi, M. Photochemical reactions of trans-anethole. Tetrahedron 1968, 24, 2183-2192.

22. Meyer, S.; Metzger, J.O. Use of electrospray ionization mass spectrometry for the investigation of radical catión chain reactions in solution: detection of transient radical cations. Anal. Bioanal. Chem. 2003, 377, 1108-1114.

23. Marquez, C.A.; Wang, H.; Fabbretti, F.; Metzger, J.O. Electron-transfer-catalyzed dimerization of trans-anethole: Detection of distonic tetramethylene radical cation intermediate by extractive electrospray ionization mass spectrometry. J. Am. Chem. Soc. 2008, 130, 17208-17209.

24. Lewis, F.D.; Bassani, D.M.; Caldwell, R.A.; Unett, D.J. Singlet state cis, trans photoisomerization and intersystem crossing of 1-arylpropenes. J. Am. Chem. Soc. 1994, 116, 10477-10485.

25. Kim, J.E.; Tauber, M.J.; Mathies, R.A. Wavelength dependent cis-trans isomerization in vision. Biochemistry 2001, 40, 13774-13778.

26. Petterson, M.; Maçôas, E.M.S.; Khriachtechev, L.; Fausto, R.; Räsänen, M. Conformational isomerization of formic acid by vibrational excitation at energies below the torsional barrier. $J$. Am.Chem. Soc. 2003, 125, 4058-4059.

27. Seydack, M.; Bending, J. The anomalous excited-state temperature behavior of trans-4,4diaminostilbene and trans-4,4-di(phenyl-ureanyl)-stilbene. J. Phys. Chem. A 2001, 105, 5731-5733.

28. Barr, J.W.; Bell, T.W.; Catalano, V.J.; Cline, J.I.; Phillips, D.J.; Procupez, R. Syntheses, structures, and photoisomerization of (E)- and (Z) -2- tert-butyl-9-(2,2,2,-triphenylethylidene)fluorine. J. Phys. Chem. A 2005, 109, 11650-11654. 
29. Arai, T.; Sakuragi, H.; Tokumaru, K. Photosensitized cis-trans isomerization of $\beta$-alkylstyrenes. B. Chem. Soc. Japn. 1982, 55, 2204-2206.

30. Norikane, Y.; Tamaoki, N. Photochemical and thermal cis-/trans- isomerization of cyclic and noncyclic azobenzene dimmers: effect of a cyclic structure on isomerization. Eur. J. Org. Chem. 2006, 1, 1296-1302.

31. Ronayette, J.; Arnaud, R.; Lebourgeois, P.; Lemaire, J. Photochemical isomerization of azobenzene in solution. Can. J. Chem. 1974, 52, 1848-1857.

32. Schultz, T.; Quenneville, J.; Levine, B.; Toniolo, A.; Martínez, T.J.; Lochbrunner, S.; Schmitt, M.; Shaffer, J.P.; Zgierski, M.Z.; Stolow, A. Mechanism and dynamics of azobenzene photoisomerization. J. Am. Chem. Soc. 2003, 125, 8098-8099.

33. Yamashita, S.; Ono, H.; Toyama, O. The cis-trans photoisomerization of azobenzene. B. Chem. Soc. Japn. 1962, 35, 1849-1853.

34. Zimmermann, G.; Ghow, L.Y.; Paik, U.J. The photochemical isomerization of azobenzene. J. Am. Chem. Soc. 1958, 80, 3528-3531.

35. Kuhn, H.J.; Braslavsky, S.E.; Schmidt, R. Chemical Actinometry. IUPAC Technical Report. Pure Appl. Chem. 2004, 76, 2105-2146.

Sample Availability: Samples of the compounds are available from the authors.

(C) 2010 by the authors; licensee MDPI, Basel, Switzerland. This article is an Open Access article distributed under the terms and conditions of the Creative Commons Attribution license (http://creativecommons.org/licenses/by/3.0/). 